\title{
Chiral Lewis Base Catalyzed Aldol Reaction of Unprotected Carboxylic Acids
}

\section{Category}

Organo- and

Biocatalysis

Key words

aldol reaction

phosphine oxides

Lewis base catalysis

carboxylic acids

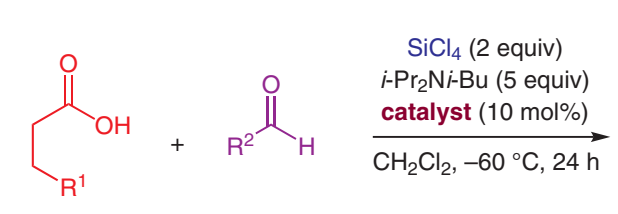

$\mathrm{R}^{1}=\mathrm{Ar}$, Alk

$$
\mathrm{R}^{2}=\mathrm{Ar}, \text { Alk }
$$

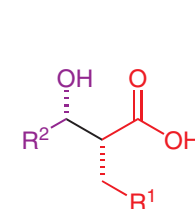

23 examples $60-84 \%$ yield $\mathrm{dr}=60: 40-99: 1$ er $=86: 14-96: 4$

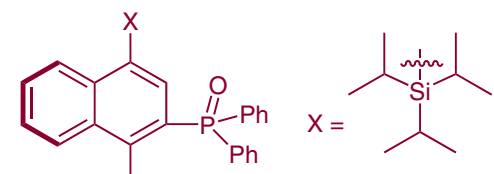<smiles>[X]c1cc(P(=O)(c2ccccc2)c2ccccc2)c(C)c2ccccc12</smiles>

\section{Selected examples:}<smiles>O=C(O)C(Cc1ccccc1)C(O)c1ccccc1</smiles>

$77 \%$ yield $\mathrm{dr}=81: 19$ er $=86: 14$<smiles>O=C(O)[C@H](Cc1ccccc1Br)[C@H](O)c1ccccc1</smiles>

$78 \%$ yield $\mathrm{dr}=91: 9$
$\mathrm{er}=90: 10$<smiles>O=C(O)[C@H](CC[N+](=O)[O-])[C@H](O)c1ccccc1</smiles>

$84 \%$ yield $\mathrm{dr}=91: 9$ er $=90.5: 9.5$<smiles>O=C(O)[C@H](CCCI)[C@H](O)c1ccccc1</smiles>

$79 \%$ yield $\mathrm{dr}=91: 9$ er $=95.5: 4.5$<smiles>O=C(O)[C@H](CCCBr)[C@H](O)c1ccc(C(F)(F)F)cc1</smiles>

$72 \%$ yield $\mathrm{dr}=86: 14$ er $=95.5: 4.5$<smiles>O=C(O)[C@H](CCCBr)[C@H](O)c1ccccc1</smiles>

$77 \%$ yield
$\mathrm{dr}=89: 11$

er $=96: 4$

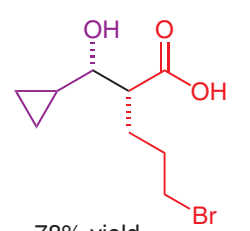

Plausible stereochemical pathway:

$\mathrm{dr}=71.29$

er $=91: 9$
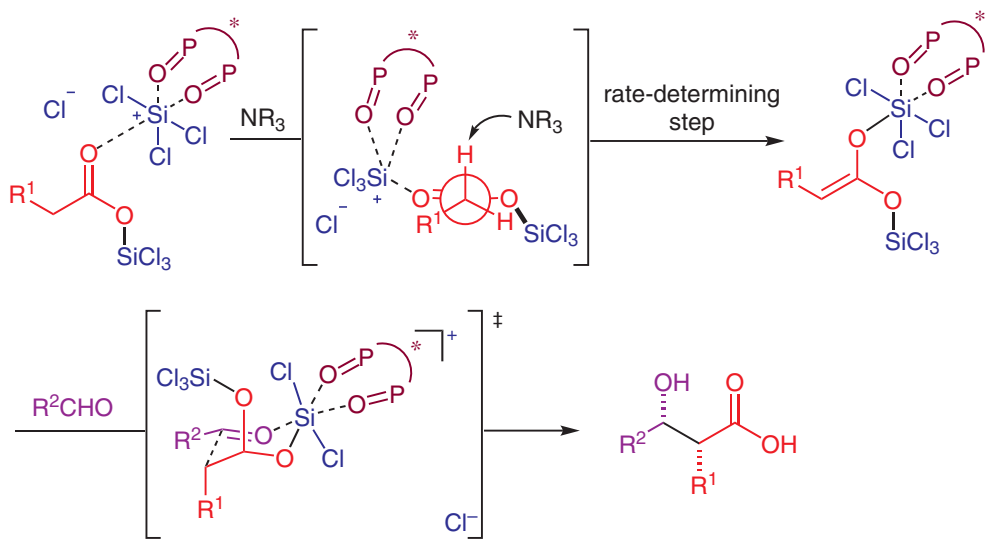

Significance: Nakajima and co-workers report the first example of a chiral Lewis base-catalyzed $\mathrm{SiCl}_{4}$-mediated enantioselective aldol reaction of unprotected carboxylic acids. The method is highly enantio- and diastereoselective, and it shows a broad substrate scope.
Comment: Previous works on asymmetric aldol reactions of unprotected carboxylic acids by various groups (see, for example: K. Yu et al. J. Am. Chem. Soc. 2017, 139, 527) required stoichiometric chiral reagents to achieve enantioselectivity, but in the presented method, the authors use $\mathrm{SiCl}_{4}$ to activate the carboxylic acid, permitting the use of only a catalytic amount of a chiral Lewis base to achieve high enantioselectivity. 